\title{
Corporal punishment and its effects in children
}

Rimal HS1, Pokharel A²

${ }^{1}$ Hem Sagar Rimal, Consultant Paediatrician, Department of Paediatrics; ${ }^{2}$ Archana Pokharel, Clinical Psychologist, Department of Psychology, Nobel Medical College Teaching Hospital, Kanchanbari-5, Biratnagar, Nepal.

Abstract

Corporal punishment in children is still a major problem throughout the globe and more common in developing countries like Nepal. Several researches done across the globe have clearly established the fact that use of corporal punishment at home, school or alternative settings is associated with higher prevalence of externalizing behaviour of youth, substance use, depression, juvenile delinquency, poor academic performance and marital conflict as an adult. Authors have reviewed the journals, websites and books to find out the magnitude of problem in the national as well as international context. It has also looked at the long-term and short term adverse effects of corporal punishment in children, current legislative status, and suggested strategies to discipline children. Reinforcing legal actions against this practice can contribute to expedite the process to end corporal punishment of children globally with strong advocacy from paediatricians and other health professionals.

Key Words: corporal punishment, child rights, legislative measures, mental health

\section{INTRODUCTION}

D hysical punishment (or corporal punishment) is defined as the use of physical force towards a child for the purpose of controlling the child's behaviour, and is often used as a punishment. It is inflicted on the child's body with the intention of causing some degree of pain or discomfort, however mild it may be ${ }^{1}$. Physical punishments most commonly consists of hitting children with hand or with kitchen utensils or belt, hitting with gas pipes and sticks but may also include kicking, biting, shaking, or forcing a child to stay in painful positions ${ }^{2}$.

In the past, it was acceptable to hit various groups of people, women (particularly by their spouse), prisoners, the mentally ill and children in schools or other care settings at various times, for the purpose of controlling

\author{
Address for correspondence: \\ Dr. Hem Sagar Rimal \\ Consultant Paediatrician \\ Department of Paediatrics \\ Nobel Medical College, Biratnagar, Nepal \\ E-mail: hemsagarr@yahoo.com
}

their undesired behaviour. The idea of administering physical punishment to these individuals is now plainly intolerable - even shocking - to most people. There has been voice raised against domestic violence from every corner of the society and from the victims as well. The only exception is children because they do not have their own voice, as a result, they are very vulnerable to corporal punishment at home, school and everywhere they live. The problem of corporal punishment in schools has a significant correlation with youth mental health problems ${ }^{3}$.

The objective of this study is to look at evidences worldwide and within the countries on corporal punishment in children and its adverse effects.

\section{METHODS}

We did an extensive search of databases (Cochrane database of systematic review, PubMed, CINHAL), Journals (psychology, psychiatry, and paediatrics), websites and books to look for evidence for thecorporal punishment in children. We also tried to explore the national and international scenario on corporal punishment, its long term effects on emotional well being of children, academic performance, mental illness and 
problems in their adulthood. The legal aspect of corporal punishment in children and management strategies has been searched extensively.

\section{BODY}

What is its situation in Nepal?

There is no explicit prohibition of corporal punishment in schools in the Education Act 1971 or the Education Regulation 2003, though Article 7 of the Children Act 1992 has prohibited severe punishment on children. Article 4 of Chapter 9 of the Muluki Ain states that guardians and teachers shall not be held responsible for hurting a child in the course of education or defence, and Article 7 of the Children Act 1992 exempts "the act of scolding and minor beating to the child by his father, mother, member of the family, guardian or teacher for the interests of the child" from the execution of cruel treatment.

\section{Prevalence research}

A powerful study "Adopting the Rights of the Child: A study on inter country adoption and its influence on child protection in Nepal" was done in 71 child centers where children, focus groups, staff of the centres and biological parents of the children were interviewed. It has found that common ways of punishing children in Nepal were hitting with physical objects, isolating them, locking them in the toilet and emotional torture, and forcefully compelling them to do cleaning works ${ }^{4}$.

In December 2003, a focus group study was conducted by the Centre for Victims of Torture, in collaboration with UNICEF, on "Existing Systems of Discipline in Schools". This study had involvement of students, teachers and parents. The study discovered that corporal punishment was very common practice in both private and public schools with higher prevalence in private schools. Primary school students were penalized commonly with physical punishment, whereas secondary level students were given psychological punishment and lower secondary students were given both types of punishment. Many teachers and parents reported that they inflicted severe punishment on children because they were unaware of alternatives to corporal punishment and knew little about the physical and psychological impacts of harsh punishments ${ }^{5}$.

\section{Corporal punishment and alternative care settings} Unfortunately, corporal punishment is lawful to some extent in alternative care settings. The legal defence was removed by the 2005 Supreme Court decision but this has not been confirmed in legislation and Article 4 of Chapter 9 of the Muluki Ain. Article 39 of the Children Act 1992 states that the powers of the chief of a children's welfare home to punish a child do not include "to batter or detain the child in solitary confinement or to stop giving food and water to such child", but does not prohibit all corporal punishment. According to the minimum Standards of Operations of Child Care, corporal punishment should not be used in residential institutions but there is no prohibition in law.

\section{International context}

Globally, more and more countries are establishing legislation that provides legal defenseagainst assault of children by parents as part of discipline and many countries are reviewing their legislation in this area. It is important to educate parents about the most effective forms of discipline that will help to guide children's behavior. Discipline should be grounded in a positive, supportive, loving relationship between the parent(s) and children, and should focus on the behavioral intervention strategies i.e. positive reinforcement strategies for the positive behaviors ${ }^{6}$.

\section{Ethical aspect}

The United Nations Convention on the Rights of the Child specifies that all the children must be protected by states from all forms of violence, including physical violence ${ }^{2}$. Inflicting physical punishment on children by an adult is a clear violation of this international convention. The UN Committee that monitors countries' implementation of the Convention regularly recommends that Governments should amend their laws and ban corporal punishment ${ }^{2}$.

In 1979 Sweden was the first country to ban all forms of corporal punishment of children unequivocally. Research has shown that since the legislative change was made, public support for physical punishment has been declining noticeably ${ }^{7}$. Sweden is an example where proportion of Swedes in favor of corporal punishment, halved between 1965 and 1981, got reduced further by $50 \%$ by 1994 after the introduction of legislation against corporal punishment. This has caused other benefits including increased early identification of children at risk of abuse, and reduction in mortality associated with child abuse. Similar kind of information was obtained from a study done by Gunnlaugsson, et al where he alsofound that 
the practice of corporal punishment of Icelandic children was significantly less prevalent among respondents born about 1980 and later compared to those born earlier, indicating that subsequent legislative measures were effective in changing the attitude of people towards corporal punishment in children ${ }^{8}$.

\section{Society's attitudes to corporal punishment}

Society's views on physical punishment are inconsistent. It is widely acknowledged that it is unacceptable for adults to hit one another, teachers and other educators to hit students, to knock people in the criminal justice system, and also to hit animals. However many people still consider it acceptable for adults to hit children as a form of discipline. The bitter fact in our society is that the only humans it is still legal to hit are the most vulnerable ones: children.

A survey of high school students in Guangzhou, China reported that the prevalence of parental psychological aggression was $78.3 \%$, corporal punishment was $23.2 \%$, severe and very severe physical maltreatment were $15.1 \%$ and $2.8 \%$ respectively. The most common reasons for maltreatment were 'disobedience to parents', 'poor academic performance', and 'quarrelling between parents'.

According to the data obtained from the Multiple Indicator Cluster Surveys (MICS) to compare different forms of child abuse across countries and regions, child abuse is found to be a very common phenomenon in many of the countries $^{10}$. There are significant differences of corporal punishment across countries, with reports of corporal punishment being lowest in Sweden and highest in Kenya ${ }^{6}{ }^{\prime \prime 1}$.The culture of corporal punishment of children is changing everywhere and the tradition approving it has been weakened and prohibition is being practiced gradually. Reinforcing legal actions against this practice can contribute to speed up the process to end corporal punishment of children globally ${ }^{6}$.

\section{Punishment and Discipline: Are they the same?}

Discipline and punishment are not the same things. The word discipline comes from a Latin word meaning "to guide". Discipline is about guiding a child so that he or she learns appropriate behavior. Punishment involves a negative experience for the child that occurs after they have done something of which the adult disapproves.
Whether or not punishment is effective in disciplining a child is debatable. It is increasingly evident that the physical punishment is not an efficient way to guide the child's behavior.

It is unquestionable that children need discipline to learn appropriate and socially acceptable behavior as they grow and develop. They require caring adults to guide them so that they learn the differences between appropriate and inappropriate behavior and strategies to regulate their own behavior. Adults responsible for children's care, particularly parents, require effective techniques to shape their children's behavior as they grow. However, it is increasingly clear that physical punishment is not an effective long term strategy for shaping children's behavior.

\section{Does corporal punishment work?}

Physical punishment doesn't appear to be superior at shaping behaviors than more positive forms of discipline ${ }^{67}$. Advocates of physical punishment may have observed that it may lead to immediate compliance but this outcome tends to be short lived, with the child learning to avoid the behavior in front of the adult, rather than actually changing their behavior ${ }^{6}$. This short term benefit of the child's, instantaneous compliance is counterbalanced by the child's failure to learn self-control and inductive reasoning ${ }^{9,12}$

A systematic review on the short-term and long-term effects of physical punishment concluded that although children are more likely to comply with adult's demands in the short term following physical punishment, they do not actually learn the desired behavior. The review also concluded that repeated and escalating levels of physical punishment may be required to sustain the desired behavioraloutcome ${ }^{13}$.

Physical punishment also teaches a child that problems can be resolved through physical aggression. It has been found that physical punishment increases the likelihood of disruptive or "bad" behaviour ${ }^{377^{\prime} 14^{\prime} 15}$.

\section{Long -term effects of corporal punishment}

1. Limited efficacy as a method of discipline: Children do not actually learn the desired behaviour through physical punishment. Instead, they learn to avoid the negative behaviour in presence of the adult. Children tend to 
learn good behaviours if there is a loving and trusting relationship with parents whose approval is important to them. The use of physical discipline can undermine the quality of a child's relationship with adults.

2. Physical punishment sends a message that aggressive behaviour is a solution to conflict ${ }^{15}$. It is an ineffective way of teaching behavioural control, but can also have serious long-term effects on children's wellbeing. Two studies from 1996 found that children who received physical punishment were more likely to experience anger related problems, physical aggression, marital dispute, problems with substance use, involvement in violence and criminal activities ${ }^{16^{\prime} 17}$. A 2002 meta-analysis showed links between physical punishment of children and risk of poor outcomes in childhood, including mental health problems, physical maltreatment, as well as several adverse outcomes in adulthood such as mental health problems, aggressive behaviour and antisocial behaviour, and abuse of own children or spouse ${ }^{16}$.

A 2012 study also found that "harsh physical punishment" is associated with mood disorders (such as depression or bipolar disorder), anxiety disorders, substance use problems and personality disorders. Between two to seven percent of different categories of disorders were estimated to be attributable to harsh physical punishment in childhood ${ }^{7}$. A study done by $\mathrm{M}$ aJ et al in Shantiago, Chile in the year 2012 found that both infrequent and frequent use of corporal punishment were positively associated with higher youth problem behaviours, but the frequent corporal punishment had stronger relationship with externalizing behaviour than the infrequent corporal punishment ${ }^{18}$.

3. Punishment and abuse: Health professionals recognize that it may be difficult to draw the line between discipline and abuse, still some jurisdiction endeavour to maintain a legal distinction.

A legal difficulty with allowing physical punishment of children is that a line must be drawn along the continuum between discipline and abuse. Many cases of physical abuse are the result of physical punishment that became more severe than intended.

It is clear that most parents who physically punish their children do not intend to harm them. They may believe that physical punishment is effective tool to manage challenging behaviours or they may not have other disciplinary tools at their disposal19. A study has found an association between families' poor parental relationship, stress and severe punishment of children ${ }^{20}$. The study done by HessCA has concluded that that the SDO (social dominance orientation) was significantly related to how an individual perceives corporal punishment ${ }^{21}$. Punishing the child physically may serve as an outlet for the parent's frustration and/or anger. This does not make it an effective way to discipline the child; that is, it does not change their behaviour in the long term. It has been found that verbal abuse was a more important predictor of conduct problems than the corporal punishment. The impact of verbal abuse was mediated differently in males and females. In case of males most of the effect of verbal abuse was mediated by low self-control, whereas anger/ frustration was the primary mediator for females ${ }^{22}$.

\section{Support for parents}

Parents may also experience other stressors that make it more challenging to adopt positive disciplinary strategies. Physical or mental health problems (whether of the parent or child), financial stress, employment difficulty and housing problems are all examples of factors that can compromise a parent's resilience and their ability to maintain a consistent and calm approach to their child's behaviour. When health professionals provide information and guidance to parents struggling with their children's behaviour, they should assess whether there are other areas in which the parent/s require additional support. Addressing other stressors may improve a parent's ability to implement positive disciplinary strategies.

\section{Role of health professionals:}

Paediatricians and other health professionals have a vital role to play in terms of taking a leadership stance on this issue. They can play an important role in educating parents about effective disciplinary strategies for children. It is very useful if the health professional can identify and respond to particular stressors in the family. Corporal punishment is still perceived as an acceptable disciplinary act by a significant proportion of physicians responsible for the health care of children, reported in a study done at Northern Israel and unexpectedly, paediatricians were found to be more tolerant of corporal punishment than family practitioners ${ }^{23}$. Behaviour problems are relatively 
common but frequently under-recognized by physicians. Hence, lots of opportunities to counsel parents about effective methods of discipline are missed. Discipline should be informative, age-appropriate and should include positive reinforcement for good behaviour ${ }^{24}$.

A suggested strategy for paediatricians is to make an observation about the child's behaviour during an outpatient visit and ask the parent(s) about the child's behaviours at homel. This may provide an opening for a balanced conversation about difficult behaviours, how they are managed, and - if necessary - how they can be managed more effectively. This can be backed up by distributing appropriate material about positive nonphysical disciplinary strategies available to parents.

Different parents may have very different expectations of children's behaviour. What is considered reasonable behaviour in one family (or even by one parent) may not be acceptable to another. Sensitivity to varying thresholds for behaviour should be taken into account. People from different cultures may also have varying expectations regarding discipline and children's behaviour. We should be discussing all these issues with families and explain in details using culturally sensitive and non-judgmental approaches.

Health professionals who work with children have a unique perspective on the harms associated with corporal punishment of children, and the potential for such practices to go sky-high. These issues are well suited to public attention, and may be able to take on roles in the media to raise the profile of this issue from a child protection perspective.

Health professionals may partner with other interested groups and do some collaborative works that have an interest in achieving changes in this area. Some highly respected organizations that base their work on

\section{REFERENCES}

1. Cashmore J, de Haas N. Legal and Social Aspects of the Physical Punishment of Children. Canberra: Department of Human Services and Health, 1995.

2. United Nations Committee on the Rights of the Child. Convention on the Rights of the Child. General comment no. 8. Geneva: General Assembly of the United Nations, 2006. scientific evidence and the best interests of children must do advocacy role by themselves or in partnership with individuals in order to get the message out that it is never acceptable to hit a child. A Study has shown that providing baby books embedded with educational information about typical child development and effective parenting in could alter new mothers' attitudes about their use of corporal punishment ${ }^{25}$.

\section{CONCLUSION}

Corporal punishment in children is still a major problem throughout the world and more common in developing counties like Nepal. Despite the possible negative effects of corporal punishment, it is still widely practiced in our society. Parental use of corporal punishment, even on an occasional basis, is associated with greater externalizing behaviourof youth, substance use, crime and depression while a warm and involving family environment may protect youth from serious problem behaviours. Reinforcing legal actions against this practice can contribute to expedite the process to end corporal punishment of children globally.

\section{RECOMMENDATIONS}

1. More awareness program needs to be introduced for parents, teachers and caregivers at the alternative care settings.

2. Strong legislative system should be established by amending the existing weak clauses.

3. Paediatricians and health care professional should utilize their contact with parents and children to screen for this problem and educate them to fight against corporal punishment in children.

4. Professional organization like Nepal Paediatric Society (NEPAS) should take initiative and provide its position statement to the government to ban corporal punishment in children.

3. Zolotor AJ, Theodore AD, Chang JJ, Berkoff MC, Runyan DK. Speak softly--and forget the stick. Corporal punishment and child physical abuse. AmJPreventive Med. 2008;35(4):364-9.

4. UNICEF and Terre des Hommes. Adopting the Rights of the Child: A study on intercountry adoption and its influence on child protection in Nepal. 2008.

5. CVICT MU. Existing Systems of Discipline in Schools. 2004. 
6. Stein MT, Perrin EL. Guidance for Effective Discipline: American Academy of Pediatrics, Committee on Psychological Aspects of Child and Family Health. Pediatrics1998; 101(4):723-728.

7. Roberts MW, Powers SW. Adjusting chair time-out enforcement procedures for oppositional children. Behavior Therapy 1990; 21:257-271

8. Durrant JE. Evaluating the Success of Sweden's Corporal Punishment Ban. Child Abuse \& Neglect 1999; 23(5): 435-448.

9. Gunnlaugsson G, Einarsdottir J. [Experience of Icelandic adults of corporal punishment and abuse in childhood]. Laeknabladid. 2013;99(5):235-9. Epub 2013/05/23

10. Akmatov MK. Child abuse in 28 developing and transitional countries--results from the Multiple Indicator Cluster Surveys. International journal of epidemiology. 2011;40(1):219-27.

11. Leung PW, Wong WC, Chen WQ, Tang CS. Prevalence and determinants of child maltreatment among high school students in Southern China: a large scale school based survey. Child and adolescent psychiatry and mental health. 2008;2(1):27.

12. Global Initiative to End All Corporal Punishment of Children. States With Full Abolition. Available at: www.endcorporalpunishment.org

13. Gershoff ET. Corporal punishment by parents and associated child behaviors and experiences: a meta-analytic and theoretical review. Psychological Bulletin 2002; 128(4):539-579.

14. Smith $A B$, Gallop MM, Taylor NJ, \& Marshall $K A$. The discipline and guidance of children: $A$ summary of research. Dunedin, NZ: Children's Issues Centre, University of Otago and the Office of the Children's Commissioner, 2004.

15. Pritchard R. Children are Unbeatable: Seven very good reasons not to hit children. New Zealand: The Office of the Children's Commissioner, UNICEF
New Zealand and the Families Commission; 2006.

16. Akmatov MK. Child abuse in 28 developing and transitional countries--results from the Multiple Indicator Cluster Surveys. International journal of epidemiology. 2011;40(1):219-27.

17. Oates K. Physical punishment of children: Can we continue to accept the status quo? Journal of Paediatrics and Child Health 2010; 47:505-507.

18. Banks JB. Childhood discipline: challenges for clinicians and parents. American family physician. 2002;66(8):1447-52.

19. Reich SM, Penner EK, Duncan GJ, Auger A. Using baby books to change new mothers' attitudes about corporal punishment. Child abuse \& neglect. 2012;36(2):108-17.

20. Ma J, Han Y, Grogan-Kaylor A, Delva J, Castillo M. Corporal punishment and youth externalizing behavior in Santiago, Chile. Child abuse \& neglect. 2012;36(6):481-90.

21. Leach P. The physical punishment of children: some input from recent research. London, National Society for the Prevention of Cruelty to Children, Policy Practice Research Series: 1999.

22. Nobes G, Smith MA. Physical punishment of children in two-parent families. Clinical Child Psychology and Psychiatry 1997; 2:271-281.

23. Tirosh E, Offer Shechter S, Cohen A, Jaffe M. Attitudes towards corporal punishment and reporting of abuse. Child abuse \& neglect. 2003;27(8):929-37.

24. Hess CA, Gray JM, Nunez NL. The effect of social dominance orientation on perceptions of corporal punishment. Journal of interpersonal violence. 2012;27(13):2728-39.

25. Evans SZ, Simons LG, Simons RL. The effect of corporal punishment and verbal abuse on delinquency: mediating mechanisms. Journal of youth and adolescence. 2012;41(8):1095-110. 